\title{
Severe Hepatotoxicity due to Ibrutinib with a Review of Published Cases
}

\author{
Zaid H. Tafesh ${ }^{\mathrm{a}} \quad$ Morton Coleman ${ }^{\mathrm{b}} \quad$ Clifton Fulmer ${ }^{\mathrm{c}} \quad$ Jerry Nagler ${ }^{\mathrm{a}}$ \\ ${ }^{a}$ Division of Gastroenterology and Hepatology, Department of Medicine, Joan \& Sanford \\ I. Weill Medical College of Cornell University, New York, NY, USA; ${ }^{b}$ Division of \\ Hematology and Oncology, Department of Medicine, Joan \& Sanford I. Weill Medical \\ College of Cornell University, New York, NY, USA; 'Department of Pathology, Cleveland \\ Clinic, Cleveland, OH, USA
}

\section{Keywords}

Case report · Hepatotoxicity $\cdot$ Acute liver injury · Drug-induced liver injury $\cdot$ Ibrutinib

\begin{abstract}
Ibrutinib, an irreversible Bruton's tyrosine kinase inhibitor, is an effective treatment for Waldenström's macroglobulinemia, chronic lymphocytic leukemia, and several other types of lymphoma. Studies prior to FDA approval in 2015 failed to demonstrate any hepatotoxicity. However, since then, there have been 2 reports in the literature of severe hepatic injury. We present a third case of a 77-year-old woman presenting with nausea and jaundice after recent discontinuation of ibrutinib and compare the presentation as well as course of all 3 known cases. The sudden onset of acute hepatotoxicity is idiosyncratic, occurring weeks after starting ibrutinib treatment. Liver biopsies in all cases revealed mixed hepatocellular and cholestatic features. Improvement progressed slowly upon discontinuation of ibrutinib. Awareness of ibrutinib hepatotoxicity, periodic surveillance of liver function tests, early recognition of any abnormalities, and prompt discontinuation of the medication are recommended.
\end{abstract}

(C) 2019 The Author(s)

Published by S. Karger AG, Basel 


\section{Case Reports in Gastroenterology}

Case Rep Gastroenterol 2019;13:357-363

DOI: 10.1159/000502605

(C) 2019 The Author(s). Published by S. Karger AG, Basel www.karger.com/crg

Tafesh et al:: Severe Hepatotoxicity due to Ibrutinib with a Review of Published Cases

\section{Introduction}

Ibrutinib is the first oral irreversible inhibitor of Bruton's tyrosine kinase. Bruton's tyrosine kinase is an enzyme located in the cytoplasm of hemopoietic cells. Following antigenic stimulation, tyrosine kinase proteins initiate a signaling cascade of reactions which ultimately lead to the release of intracellular calcium, diacylglycerol, and inositol triphosphate that subsequently increase nuclear factor kappa B to inhibit apoptosis and promote replication [1]. Blockage of Bruton's tyrosine kinase inhibits B cell maturation, differentiation, and migration. Ibrutinib has been proven to be effective in the treatment of chronic lymphocytic leukemia, mantle cell lymphoma, marginal zone lymphoma, and Waldenström's macroglobulinemia [24].

Ibrutinib is generally very well tolerated. Reported adverse reactions include diarrhea, nausea, fatigue, arthralgias, hypertension, rash, and bruising [5]. More serious (grade 3-4) reactions consist of atrial fibrillation, neutropenia with upper respiratory or sinus infections, and a bleeding tendency due to platelet dysfunction [6-8]. Diarrhea is the most common side effect but often diminishes over time [9]. Hepatic toxicity was not reported prior to FDA approval in 2015. However, since then, there have been 2 case reports of severe acute liver injury associated with ibrutinib treatment in patients, one with chronic lymphocytic leukemia and the other with Waldenström's macroglobulinemia. We present another case of ibrutinib hepatotoxicity in a patient with Waldenström's macroglobulinemia and compare the presentation, course, and resolution of all 3 cases.

\section{Case Report}

A 77-year-old woman was admitted to the hospital with jaundice and nausea. She had been started on ibrutinib treatment for Waldenström's macroglobulinemia with associated anti-factor VIII antibody approximately 2 months prior. This medication was discontinued 9 days before admission because of the onset of nausea and epigastric discomfort. Two days preceding admission, she noted yellow skin and increasing fatigue. There was no history of alcohol abuse, use of non-prescription or herbal medications, nor previous liver or gallbladder conditions. On examination, she was noted to be afebrile and jaundiced but alert and fully oriented without spider angiomata, palmar erythema, or asterixis. Liver function tests were markedly abnormal with total bilirubin $10.6 \mathrm{mg} / \mathrm{dL}$ (normal $0.3-1.2 \mathrm{mg} / \mathrm{dL}$ ), direct bilirubin $8.5 \mathrm{mg} / \mathrm{dL}$ (normal $<0.3 \mathrm{mg} / \mathrm{dL}$ ), alanine aminotransferase (ALT) 1,747 U/L (normal 10-49 $\mathrm{U} / \mathrm{L}$ ), aspartate aminotransferase (AST) 1,300 U/L (normal <34 U/L), alkaline phosphatase $200 \mathrm{U} / \mathrm{L}$ (normal 32-91 U/L), and international normalized ratio (INR) 1.5 (normal 0.9-1.1). The MELD-Na score was 25. An abdominal-pelvic CT scan revealed periportal edema and ascites, normal common bile duct, complex right renal cyst, small hiatal hernia, and colonic diverticulosis. An abdominal sonogram was normal except for several small hyperechoic liver lesions, and an abdominal MRI scan showed the presence of liver hemangiomas, hepatocyte dysfunction, and a thickened gallbladder wall. Blood tests were negative for infection with hepatitis A, B, and C as well as CMV, HSV, and EBV. Anti-smooth muscle antibody was negative, but ANA was positive. A transjugular liver biopsy was performed, which demonstrated evidence of a mixed inflammatory cell infiltrate, lobular disarray, hepatocellular ballooning, focal 


\section{Case Reports in Gastroenterology}

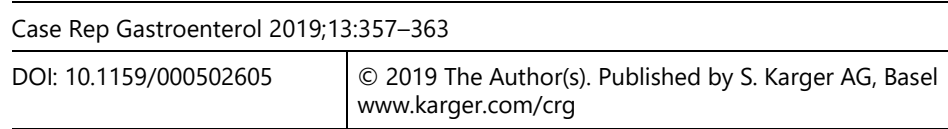
www.karger.com/crg

Tafesh et al:: Severe Hepatotoxicity due to Ibrutinib with a Review of Published Cases

canalicular cholestasis, and necrosis, all consistent with a drug-induced liver injury (Fig. 1ad).

The patient was started on treatment with prednisone $60 \mathrm{mg}$ daily. She began feeling better shortly afterwards, without nausea and with increased energy. After 12 days, the ALT decreased to $635 \mathrm{U} / \mathrm{L}$, AST decreased to $413 \mathrm{U} / \mathrm{L}$, alkaline phosphatase was unchanged at 205 $\mathrm{U} / \mathrm{L}$, but the total bilirubin increased to $20.4 \mathrm{mg} / \mathrm{dL}(16.3 \mathrm{mg} / \mathrm{dL}$ direct). The patient was discharged to close outpatient follow-up on prednisone $50 \mathrm{mg}$ daily. This dose was reduced by $10 \mathrm{mg}$ weekly until $20 \mathrm{mg}$ daily, then tapered off by decreasing the dose $5 \mathrm{mg}$ weekly. After 7 weeks, the liver function tests normalized with total bilirubin $1.2 \mathrm{mg} / \mathrm{dL}$, alkaline phosphatase $58 \mathrm{U} / \mathrm{L}, \mathrm{ALT} 25 \mathrm{U} / \mathrm{L}$, and AST $24 \mathrm{U} / \mathrm{L}$. The patient was asymptomatic at this time. Repeat liver function tests obtained 3 months later confirmed that they remained within normal limits (total bilirubin $0.4 \mathrm{mg} / \mathrm{dL}$, alkaline phosphatase $58 \mathrm{U} / \mathrm{L}$, ALT $8 \mathrm{U} / \mathrm{L}$, and AST $12 \mathrm{U} / \mathrm{L}$ ).

\section{Discussion}

Comparison of our case with the 2 other reported cases of ibrutinib hepatotoxicity [10, 11] revealed the age range at presentation to be 59-77 years old, including 1 male and 2 female patients (Table 1). Two patients were being treated for Waldenström's macroglobulinemia and 1 for chronic lymphocytic leukemia. The onset of liver injury was idiosyncratic with a latency period of between 2 and 36 weeks from the beginning of ibrutinib treatment. Shortly afterwards liver toxicity was detected, all 3 patients had very high ALT levels $(>1,000 \mathrm{U} / \mathrm{L}), 2$ had a coagulopathy (elevated INR), and 1 had encephalopathy, indicating severe liver damage in all 3 patients. Liver biopsies all showed hepatocellular injury in the centrilobular region, caused by a mixed inflammatory cell infiltrate, and additional canalicular cholestasis. This was reflected in the serum liver function tests, which initially were characterized by marked elevations of aminotransferase and later on by increased alkaline phosphatase and bilirubin. Resolution of the abnormal liver function tests was slow following discontinuation of ibrutinib, taking from 60 to 120 days, with 1 patient receiving corticosteroids. Two patients fully recovered, while the patient with chronic lymphocytic leukemia improved but died of his underlying illness. Of interest, 4 cases of idiosyncratic ibrutinib pneumonitis successfully treated with drug withdrawal and corticosteroids have also been reported [12].

A variety of tyrosine kinase inhibitors have been approved and found to be highly effective in the treatment of cancer patients. Unfortunately, the majority of these drugs have been shown to cause some degree of hepatotoxicity [13, 14]. Prior to FDA approval in 2015, there was no evidence of hepatotoxicity caused by ibrutinib. Since then, there are now 3 reported cases. Further improvements in cultured liver cell models may provide earlier detection of potential drug-induced liver toxicity [15]. Increased liver damage from ibrutinib will occur if not detected early, since it is metabolized in the liver by the P450 cytochrome enzyme CYP3A [16], and, therefore, drug levels will rise once liver damage has commenced. The manufacturer recommends dose reduction in patients with known mild liver disease or concomitant medications which inhibit CYP3A and complete avoidance in patients with moderate to severe liver disease. Fortunately, the liver damage abates after the medication is withdrawn, but continued drug exposure may lead to serious liver failure. All patients treated with ibrutinib should 
be monitored periodically with serum liver function tests and the drug discontinued immediately if there is no other apparent cause for an elevation.

\section{Statement of Ethics}

Written informed consent for case report write-up was obtained from the patient. A copy of the signed consent form remains with the authors. Our Medical School's institutional review board reviewed and approved the article prior to submission for publication.

\section{Disclosure Statement}

Dr. Morton Coleman is a speaker for Pharmacyclics and on their advisory board. He also receives research support from Pharmacyclics. Drs. Zaid H. Tafesh, Jerry Nagler, and Clifton Fulmer have no conflicts of interest to disclose.

\section{Funding Sources}

There was no source of funding for this article.

\section{Author Contributions}

Zaid H. Tafesh and Jerry Nagler wrote, revised. and edited the final manuscript. Jerry Nagler also collected patient data and obtained informed consent from the patient for case write-up. Morton Coleman reviewed and edited the manuscript. Clifton Fulmer supplied the pathology slides and provided the text for the captions accompanying the slides.

\section{References}

1 Lee CS, Rattu MA, Kim SS. A review of a novel, Bruton's tyrosine kinase inhibitor, ibrutinib. J Oncol Pharm Pract. 2016 Feb;22(1):92-104.

2 Itchaki G, Brown JR. Experience with ibrutinib for first-line use in patients with chronic lymphocytic leukemia. Ther Adv Hematol. 2018 Jan;9(1):3-19.

3 Castillo JJ, Palomba ML, Advani R, Treon SP. Ibrutinib in Waldenström macroglobulinemia: latest evidence and clinical experience. Ther Adv Hematol. 2016 Aug;7(4):179-86.

4 Coutré SE, Furman RR, Flinn IW, Burger JA, Blum K, Sharman J, et al. Extended treatment with single-agent ibrutinib at the $420 \mathrm{mg}$ dose leads to durable responses in chronic lymphocytic leukemia/small lymphocytic lymphoma. Clin Cancer Res. 2017 Mar;23(5):1149-55.

5 Byrd JC, Furman RR, Coutre SE, Flinn IW, Burger JA, Blum KA, et al. Targeting BTK with ibrutinib in relapsed chronic lymphocytic leukemia. N Engl J Med. 2013 Jul;369(1):32-42.

6 Byrd JC, Furman RR, Coutre SE, Burger JA, Blum KA, Coleman M, et al. Three-year follow-up of treatmentnaïve and previously treated patients with CLL and SLL receiving single-agent ibrutinib. Blood. 2015 Apr;125(16):2497-506. 


\section{Case Reports in Gastroenterology}

Tafesh et al:: Severe Hepatotoxicity due to Ibrutinib with a Review of Published Cases

7 Wang ML, Blum KA, Martin P, Goy A, Auer R, Kahl BS, et al. Long-term follow-up of MCL patients treated with single-agent ibrutinib: updated safety and efficacy results. Blood. 2015 Aug;126(6):739-45.

8 Treon SP, Tripsas CK, Meid K, Warren D, Varma G, Green R, et al. Ibrutinib in previously treated Waldenström's macroglobulinemia. N Engl J Med. 2015 Apr;372(15):1430-40.

9 Davids MS, Brown JR. Ibrutinib: a first in class covalent inhibitor of Bruton's tyrosine kinase. Future Oncol. 2014 May;10(6):957-67.

10 Nandikolla AG, Derman O, Nautsch D, Liu Q, Massoumi H, Venugopal S, et al. Ibrutinib-induced severe liver injury. Clin Case Rep. 2017 Mar;5(6):735-8.

11 Kahn A, Horsley-Silva JL, Lam-Himlin DM, Reeder CB, Douglas DD, Carey EJ. Ibrutinib-induced acute liver failure. Leuk Lymphoma. 2018 Feb;59(2):512-4.

12 Mato AR, Islam P, Daniel C, Strelec L, Kaye AH, Brooks S, et al. Ibrutinib-induced pneumonitis in patients with chronic lymphocytic leukemia. Blood. 2016 Feb;127(8):1064-7.

13 Shah RR, Morganroth J, Shah DR. Hepatotoxicity of tyrosine kinase inhibitors: clinical and regulatory perspectives. Drug Saf. 2013 Jul;36(7):491-503.

14 Lee KW, Chan SL. Hepatotoxicity of targeted therapy for cancer. Expert Opin Drug Metab Toxicol. 2016 Jul;12(7):789-802.

15 Lin C, Khetani SR. Advances in Engineered Liver Models for Investigating Drug-Induced Liver Injury. BioMed Res Int. 2016;2016:1829148. Epub 2016 Sep 20.

16 de Weerdt I, Koopmans SM, Kater AP, van Gelder M. Incidence and management of toxicity associated with ibrutinib and idelalisib: a practical approach. Haematologica. 2017 Oct;102(10):1629-39. 


\section{Case Reports in Gastroenterology}

Case Rep Gastroenterol 2019;13:357-363

Tafesh et al.: Severe Hepatotoxicity due to Ibrutinib with a Review of Published Cases
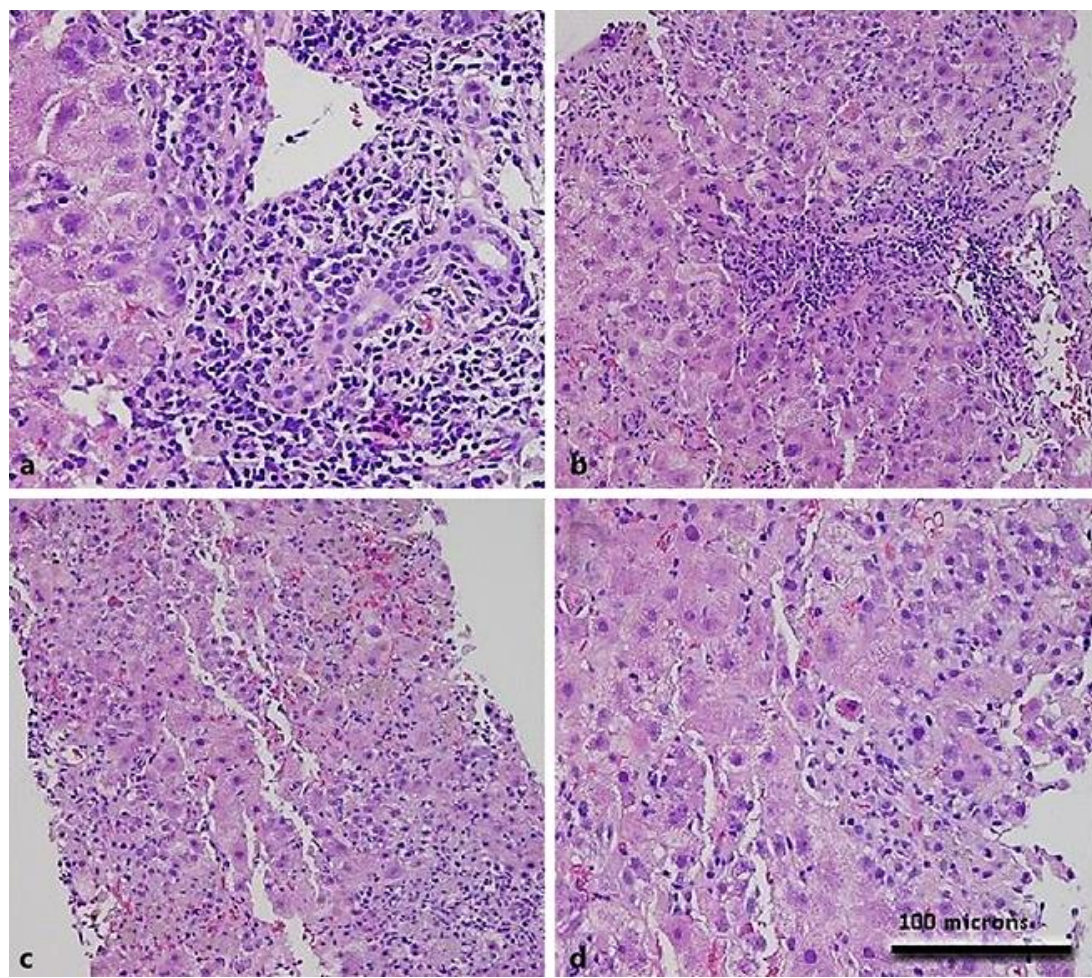

Fig. 1. Pathologic changes of ibrutinib-related liver injury on biopsy. a Inflamed portal tract with abundant lymphocytes, plasma cells, and eosinophils. b Additional portal tract with interface activity and injury surrounding lobular parenchyma. c Lobular injury with disarray and collapse. Marked cholestasis. d Acidophil bodies and hepatocellular ballooning. 
 Gastroenterology}

\begin{tabular}{l|l}
\hline Case Rep Gastroenterol 2019;13:357-363 \\
\hline DOI: 10.1159/000502605 & $\begin{array}{l}\text { ○ 2019 The Author(s). Published by S. Karger AG, Basel } \\
\text { www.karger.com/crg }\end{array}$ \\
\hline
\end{tabular}

Tafesh et al:: Severe Hepatotoxicity due to Ibrutinib with a Review of Published Cases

Table 1. Comparing 3 reported cases of hepatotoxicity secondary to ibrutinib

\begin{tabular}{|c|c|c|c|}
\hline Case No. & 1 & 2 & 3 \\
\hline Underlying illness & $\begin{array}{l}\text { Chronic lymphocytic } \\
\text { leukemia }\end{array}$ & $\begin{array}{l}\text { Waldenström's } \\
\text { macroglobulinemia }\end{array}$ & $\begin{array}{l}\text { Waldenström's } \\
\text { macroglobulinemia }\end{array}$ \\
\hline Age, years & 62 & 59 & 77 \\
\hline Sex & Male & Female & Female \\
\hline Abnormal liver function test onset & 2 weeks & 36 weeks & 8 weeks \\
\hline ALT peak, U/L & 1,245 & $\sim 800$ & 1,747 \\
\hline AST peak, U/L & 448 & $\sim 3,000$ & 1,300 \\
\hline Total bilirubin peak, mg/dL & 35.2 & 13.6 & 20.4 \\
\hline INR peak & Not specified & 7.7 & 1.5 \\
\hline Liver biopsy & $\begin{array}{l}\text { Hepatocellular injury + } \\
\text { cholestasis }\end{array}$ & $\begin{array}{l}\text { Hepatocellular injury + } \\
\text { cholestasis }\end{array}$ & $\begin{array}{l}\text { Hepatocellular injury + } \\
\text { cholestasis }\end{array}$ \\
\hline Recovery time & 12 weeks + & 9 weeks & 7 weeks \\
\hline Outcome & $\begin{array}{l}\text { Died from original } \\
\text { illness }\end{array}$ & Full recovery & Full recovery \\
\hline
\end{tabular}

